\title{
Los comienzos literarios del cineasta Octavio Getino: realismo y deshumanización en Cbulleca
}

\section{The Literary Beginning of Filmmaker Octavio Getino:} Realism and Dehumanization in Cbulleca

\author{
Juan Camilo Lee Penagos*
}

Resumen: En este artí́culo se analiza el libro de cuentos Chulleca (1964) de Octavio Getino, reconocido cineasta, quien empezó su carrera como artista en el campo de la literatura. Se destaca la manera en que esta narrativa se inscribía en las discusiones políticas y estéticas del momento, tanto en Argentina como en Latinoamérica. Esta serie de cuentos ofrece una mirada sobre la "cosificación" y la "alienación" de los obreros, su "deshumanización", en donde recuerda reflexiones de cuño marxiano, que a su vez evocan las propuestas de la filosofía descolonial de Enrique Dussel. El hallazgo radica en que este artículo sería el primer estudio publicado sobre Chulleca.

PalaBRAS CLAVE: Literatura Latinoamericana; Casa de las Américas; Arte y Políitica.

ABSTRACT: Octavio Getino, a well-known filmmaker, started his trajectory as an artist in the literary world. This article studies his first and only short stories book Chulleca (1964), pointing the way it is inscribed in the political and aesthetical discussions, in Argentina and Latin America. The book presents a look at the "reification" and "alienation" of workers, their "dehumanization", recalling Marxist ideas and the philosophy of Enrique Dussel. As we know, this is the first study of Getino's book.

KEY wORDS: Octavio Getino; Latin American Literature; Casa de las Américas; Arts and Politics.

Recibido: 19 de octubre de 2018

Aceptado: 25 de febrero de 2019

Universidad Nacional de Colombia (juancamilolee@gmail.com). 


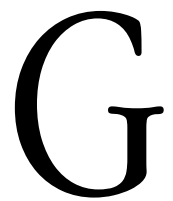

etino migró hacia Argentina en 1952, muy joven, huyendo de la dictadura franquista, pues su familia era socialista. Desde su llegada, se vinculó con asociaciones republicanas - antiperonistas en cuanto asociaban a Franco con Perón-al tiempo que empezaba su producción como escritor. Comenzó su militancia política desde el Centro Republicano Español, allí editaba un periódico llamado El Quijote, junto con otros jóvenes con padres republicanos llegados a Argentina. Getino ejercía el cargo de secretario de Prensa de la Juventud Española Republicana en el Exilio. Según el mismo Getino, este era un "título excesivo para lo que en realidad representábamos: algo menos de una veintena de hijos de exiliados e inmigrantes" (Getino 2010). En general, debido al régimen franquista en España, para los exiliados que llegaron a Argentina en varias oleadas desde finales de los años treinta el régimen de Perón (1943-1955) se vivió como la versión latinoamericana del de Franco (Schwarzstein 2001: 92). Sectores intelectuales y políticos antiperonistas recibieron y apoyaron de buena manera a estos exiliados: los partidos Comunista, Socialista y Radical, junto con el círculo que se reunía alrededor de Victoria Ocampo y la revista Sur, mantuvieron constante relación con los republicanos en Argentina $(104,121)$. Sin embargo, al terminar la década larga del peronismo en el poder, Getino empezó a dar un giro en sus apreciaciones políticas, se distanció de esa mirada antiperonista, y comenzó a militar en sectores sindicalistas (Getino 2010) de filiación peronista. También continuó con su trabajo literario.

El primer premio de cuento que ganó Getino fue el convocado por la revista El Escarabajo de Oro, dirigida por Abelardo Castillo, en 1962, con un cuento que hizo parte del libro que se estudiará en este artículo: Chulleca. Este premio de cuento fue compartido con cuatro cuentos de otros autores como Ricardo Piglia o Miguel Ángel Briante. Esta revista era heredera de El Grillo de Papel, otra publicación sobre literatura también dirigida por Castillo, que por cuestiones de censura había debido clausurarse bajo la mano dura que el gobierno de Arturo Frondizi aplicaba mediante el plan Conintes (Conmoción Interna del Estado) (Calabresse 2006: 47). Frondizi, que desde el comienzo de su gobierno había tenido que lidiar 
con la presión de los militares antiperonistas a la vez que negociar con las organizaciones sindicales peronistas (a las cuales debía en buena parte su triunfo electoral), en 1960, con tal plan de conmoción, había terminado cediendo a la presión militar. Esto se tradujo en el control militar del creciente movimiento obrero (Romero 2013: 76) (Bethel 2002: 87-88). En esta misma tónica, Frondizi también había proscrito con anterioridad las actividades del Partido Comunista. Como El Grillo de Papel se inscribía en un conjunto de publicaciones que intentaban hacer una nueva lectura del peronismo y de la situación del país desde una mirada de izquierda alternativa (Sigal 1991: 129), debió ser cerrada bajo el peso de la censura en 1960. Castillo continuó con su proyecto editorial, simplemente cambiándole el nombre a El Escarabajo de Oro, en 1961. Esta revista, si bien se desligaba de la influencia del Partido Comunista, también se enfrentaba al grupo de la revista Sur, dirigida por Victoria Ocampo, de cuño liberal y antiperonista. Según lo comenta José Luis de Diego en su tesis doctoral (De Diego 2003: 58) para hacer esta doble diferenciación, en la revista de Castillo se utiliza un criterio realista amplio: "la reivindicación del realismo partía de una concepción muy amplia del mismo y no era mucho más que un arma de combate contra la otra tradición, identificada con el grupo Sur". En agosto de 1962, ya cuando Frondizi había sido depuesto por los militares, y en su reemplazo ejercía la presidencia José María Guido, en el número 6 de la revista es lanzado su segundo concurso de cuento, y en enero de 1963 aparecen los resultados: cinco ganadores, todos con cuentos que se podrían ajustar a una definición amplia de "realismo". ${ }^{1}$

1 Sobre el tema del "realismo" y la aparición de "lo real" en la literatura argentina, puede ser muy significativo el texto de Ángel Rama "Rodolfo Walsh: las narrativas en el conflicto de las culturas". Allí, el crítico uruguayo argumenta que lo "valerosamente real" que empieza a aparecer en la literatura argentina desde la década de los cincuenta se puede rastrear en una especie de genealogía que va desde Leopoldo Marechal, pasa por Julio Cortázar y termina con Rodolfo Walsh. Este aspecto "realista" es relacionado por Rama con la aparición de características culturales correspondientes a las "clases dominadas", en medio de una producción literaria enmarcada en la cultura de "los dominantes". Así, lo "realista" se podría relacionar con la cultura de las clases bajas, populares y, en contexto argentino, peronistas. La genealogía que traza "grosso modo" Rama señala la progresiva aparición de tal cultura, que tiene su culmen en la 
Podríamos tomar una muy útil definición sobre el "realismo" de tendencia marxiana que Carlo Salinari da en su prólogo a la compilación de textos de Marx y Engels sobre arte:

El arte realista, en efecto, es aquel que, cuando una clase ha establecido su hegemonía y ha hecho oficial (universal y eterno) un modo propio de juzgar la realidad, de concebir las relaciones sociales, de valorar los mismos comportamientos individuales, rompe el telón de oficialidad, establece una confrontación entre la falsa y edulcorada representación de lo real proporcionada por la clase dominante con los datos de la situación concreta, desmitifica los llamados valores universales y especifica todos sus aspectos y todas sus contradicciones. Es natural que un arte semejante resulte congenial con las fuerzas que en esa misma sociedad luchan por destruir la situación existente y establecer un orden nuevo (Salinari 1969: 12).

Así el "realismo", no sólo es un intento por dar un retrato de lo que ocurre, sino de presentar aspectos de eso que ocurre que estén ocultos, prohibidos, negados, escondidos. En este sentido, el cuento de Getino, como se verá, expresaba esa realidad que se intentaba reprimir mediante el Conintes.

literatura walshiana, que pone en cuestión la definición misma de literatura. Si se nos presionara para ubicar Chulleca en esta genealogía, podríamos decir que se encuentra entre Cortázar y Walsh, en cuanto se perciben características locales y populares, pero no llegan a tener la presencia y contundencia que tienen en la obra walshiana. Se podría decir que están más cerca de este último que de Cortázar en cuanto a que la presencia de lo político es fuerte. A nivel latinoamericano, como lo muestra Claudia Gilman (2003: 317-321), y como se verá, la discusión sobre el realismo fue candente y de importancia considerable. La crítica se interesó por ampliar las nociones de realismo, de quitarle el peso "prescriptivo" con el que contaba gracias al estalinismo, y por tratar de aunarlo, hasta donde fue posible, con el término "vanguardia". Entre los autores que marcaron hitos en esta discusión con sus obras podemos mencionar a Carlos Onnetti, Juan Rulfo, Carlos Fuentes y Alejo Carpentier, entre otros. Si bien Chulleca no tiene las características de "vanguardia" que se podrían encontrar en las obras de los autores mencionados, es innegable que se inscribe en las discusiones sobre realismo que se dieron en la época. 
En cuatro de los cinco cuentos ${ }^{2}$ los personajes principales son marginales en la sociedad: campesinos despojados, emigrados en la ciudad, obreros pobres. Sin embargo, en el único cuento en el que explícitamente se trata la situación políica del país en esos años es en el de Getino. El cuento trata de un empleado de una fábrica, anónimo, que pasa desapercibido frente a sus compañeros, y que por cuestiones del azar termina involucrado directamente en una fuerte protesta obrera en la ciudad. El personaje termina asesinado por la violencia policial, y se convierte en una especie de héroe póstumo para el movimiento sindical. Su involucramiento en la protesta, y su instintivo actuar dentro de ella, transcurren como si "45" (es el apodo del personaje, su gigantesca talla de zapatos) fuera incapaz de ejercer algún tipo de control sobre su destino. Éste había llegado desde Tucumán a Capital Federal por el cierre del ingenio donde trabajaba, su mujer se le "había pegado una noche" y a la tarde "estaba con una piba en brazos" y, en la protesta, alguien "le hablaba a él, que hubiese querido explicar que no tenía nada que ver en el asunto. Pero no dijo nada" y luego "Le pidieron ayuda como si estuviera obligado a darla. Titubeó. Y titubeando, aceptó. Como si no pudiera evadirse" (Getino 1964: 102). Su posterior enfrentamiento cara a cara con un policía a caballo parece del todo inconsciente, instintivo, nunca una decisión racional: "Agarró una baldosa. Sintió su superficie cortante, fría, adhiriéndose a la palma de la mano. Incrustándose en la carne. Los dedos engarfiados. La mirada indecisa. Tensas las piernas. iAsí! La resolución bajó atravesando el rostro, recorrió el antebrazo y su mano endurecida se elevó con toda su fuerza escupiendo la baldosa contra uno de los cascos. O el cielo. Tan juntos estaban" (103). Su muerte ocurre casi inmediatamente después de su instintiva rebelión: un policía a caballo lo acribilla a sablazos.

Es importante notar que el personaje no es heroico, ni pertenece a sindicato alguno. Más bien es un tipo dócil, que prefiere no ir al seguro médico después de un accidente de trabajo, para que no lo tomaran "en-

2 El premio fue compartido por Octavio Getino con "Le decían 45", Ricardo Piglia con "Mi amigo", Miguel Ángel Briante, con "Kincón", Juan Carlos Villegas con "Las aristas del tiempo" y Germán Rozenmacher con "Los pájaros salvajes". 
tre ojos" (Getino 164: 100). El cuento no es una idealización de la militancia sindical, ni una adulación al luchador social. Es más bien una postal de la insignificancia de la vida del obrero, que incluso cuando logra rebelarse y actuar en contra de aquellos que le oprimen, sigue estando bajo su yugo. No es tampoco la historia de una "toma de conciencia" en donde el obrero asumiera para su propio beneficio su condición de proletario. El cuento más bien apunta a ubicar la posibilidad de rebelión obrera en el nivel de lo inconsciente, como una reacción y no como una decisión. Otro punto a destacar, puesto que se repetirá en los cuentos del libro Chulleca con el que ganará el concurso en Cuba, es la relación que el narrador establece entre la muerte de "45" y la máquina que él opera en la fábrica. Al momento de recibir el sablazo, el narrador nos recuerda que "Era la misma hora en que la "Cincinnati" doblaba una chapa con seco chasquido. Cerca de ella una pulidora aullaba entre un raudal de chispas" (Getino 1994: 104). Este salto espacial en la narración, esta mención de la sincronicidad de estos dos eventos, es única en el relato. Esta relación entre la muerte de un obrero y el funcionamiento de la máquina que él opera parece apuntar a resaltar aún más la insignificancia del personaje, la manera en que la "Cincinnati" sigue funcionando aun cuando el obrero haya muerto, insinuando, como veremos, una visión marxiana de la relación entre el trabajador y la máquina. Es una especie de "deshumanización” del obrero, que se convierte en simple objeto de las necesidades del ingenio - que prescinde de él cuando hay sobreproducción de azúcar-, simple operario de una máquina que sigue doblando chapas a pesar de su muerte, o que es asesinado cuando por azar o reacción impensada se rebela contra su destino.

Como se decía, el gobierno de Frondizi, a partir de 1960, había arreciado su ofensiva contra los sectores obreros, y contra la labor política de la izquierda comunista. A partir de la proscripción del peronismo como partido político desde 1955 por la Revolución Libertadora, la militancia sindical obrera se había convertido en uno de los bastiones principales del movimiento político popular liderado por Perón desde el exilio. Las "62 organizaciones" sindicales se convirtieron desde 1957 en el instrumento 
a través del cual el peronismo intentó recuperar el control de los gremios obreros, convirtiendo a estas organizaciones en un "actor central de la vida política argentina" (Bethel 2002: 79). Y aunque en los comienzos del gobierno de Frondizi los sectores obreros fueron beneficiados, las presiones de los militares no se hicieron esperar, provocando nuevas constricciones sobre los sindicatos. Este "estira y afloja" entre sindicatos, gobierno y fuerzas militares terminó en el represivo Plan Conintes, además de, paradójicamente, en un creciente descontento de los militares por la ambigüedad frondizista. Todo esto, vale la pena resaltarlo, ambientado por el impacto internacional de la Revolución cubana, que amenazaba con expandir su radicalidad a toda Latinoamérica, lo que exacerbaba los temores militares. Así pues, para el año en que se publicaba el cuento de Getino, las organizaciones sindicales peronistas llevaban años resistiendo los embates patronales, ya fuera desde el gobierno de facto de la Revolución Libertadora, o desde el desarrollismo frondizista. Esto había provocado, desde los primeros años de la proscripción, que las posturas clasistas y más radicales se acentuaran dentro de las organizaciones peronistas:

Para comprender el proceso en Argentina, es necesario tener en cuenta que para este momento, producto de los años de proscripción del movimiento en que los trabajadores se referenciaban de forma mayoritaria, dentro del peronismo se profundizaban ciertos debates y posicionamientos clasistas, y la tendencia revolucionaria dentro del mismo comenzaba a consolidarse organizativamente, y a articularse con otras organizaciones políticas y sociales combativas (Scodeller 2003: 163).

Getino, cuya formación política era eminentemente sindical, ${ }^{3}$ no podía ser ajeno a estas tendencias. Desde un socialismo republicano y antiperonista, hasta un sindicalismo peronista que se radicalizaba de manera

3 Dice Getino en la entrevista que le dio a Javier Campo: "Participé de la militancia sindical en una fábrica que tenía Di Tella en Monte Chingolo, producía lavarropas, ventiladores y después automóviles. Fui dirigente y candidato a secretario adjunto en las elecciones sindicales. O sea, participé de la resistencia desde una posición de izquierda vinculada al peronismo, pero que no poseía la concepción teórica metodológica formal, práctica, de La Resistencia de años posteriores" (Campo 2013: 126). 
clasista, la trayectoria política de Getino, con el premio en El Escarabajo de Oro, se cruzaba con la de un sector de la izquierda intelectual que se alejaba del Partido Comunista para reconsiderar de manera menos tajante al peronismo. Esto con un cuento que trata de un obrero cobarde que, después una fugaz rebeldía, es asesinado a sablazos por un policía sobre un caballo en una calle de la Capital. A través de su "realismo" no heroico, el cuento a la vez se oponía a la estética que proponían los círculos liberales - como Sur - y se alejaba también de una literatura panfletaria de izquierda.

\section{EL LIBRO: ENTRE CUBA Y ARGENTINA}

Según Silvia Sigal (1991: 132), después de la caída del peronismo, en algunos pequeños grupos intelectuales se empezaron a recorrer caminos argumentativos y militantes que iban desde el nacionalismo al marxismo o viceversa, en diferentes intentos de encontrar nuevos puntos de vista a una situación política también nueva. Los cuentos de Getino retratan a la clase obrera y trabajadora desde un punto de vista menos "nacionalista" y más dado a una mirada de izquierda clasista. El libro Chulleca muestra a tal sector social de una manera que recuerda ciertas conceptualizaciones y análisis específicamente marxianos. ${ }^{4}$

En general, los cuentos de Chulleca tienen un tono muy parecido al premiado en El Escarabajo de Oro: muestran, casi todos, de manera más o menos "realista", a miembros marginales de la sociedad que, sin convertirse en héroes, muchas veces alcanzan un momento significativo de libertad o rebeldía. En ellos se ahonda en la relación entre el obrero y la máquina, entre el ser humano y el animal, o entre el sujeto y los mecanismos del poder. El tema que parece atravesar todos los relatos es el de la "deshumanización" o "cosificación" del ser humano, sobre todo en el

4 Acogemos acá la diferenciación entre marxiano y marxista: el segundo se relaciona con la militancia política, el primero con ideas o tradiciones de pensamiento que se apoyan en las obras de Marx. 
ambiente fabril. Es difícil no pensar, al leer los relatos, en las concepciones marxianas que oponen el trabajo al capital, y que muestran cómo el trabajo asalariado capitalista niega la humanidad del trabajador mientras humaniza o "fetichiza" las cosas. El libro fue premiado por el concurso de cuento promovido en Cuba por la Casa de las Américas en 1964, e incluía el cuento ganador del concurso impulsado por la revista argentina El Escarabajo de Oro. Para ese momento, ya Frondizi había sido depuesto por el poder militar. En su reemplazo había ascendido momentáneamente José María Guido - presidente del congreso en el momento del derrocamiento a Frondizi- para luego, en 1963, convocar a elecciones en donde resultaría electo Arturo Illía, con el peronismo nuevamente proscrito. Este último asumiría una actitud radical cuando, desde las 62 Organizaciones, se planteaba un plan de lucha

en torno a la libertad de los detenidos por razones políticas, la vigencia de las leyes de previsión social, la participación de los trabajadores en la dirección de las empresas, la fijación de precios máximos para los artículos de primera necesidad, la reforma agraria, la anulación de contratos petroleros y el retorno a la Constitución Nacional. De este modo, se ordenó una primera semana de paros para mayo de 1963, en el marco de la primera etapa del Plan de Lucha. [...] A los pocos meses de su gestión, el joven gobierno [de Illía] tuvo que hacer frente a un nuevo enfrentamiento de la central laboral. Además de las anteriores demandas, se agregó el pedido de que la administración radical sancione la ley del salario mínimo, vital y móvil. Así, a través de sucesivas jornadas, se dispuso la realización de la segunda etapa

5 En una nota en la publicación periódica uruguaya Marcha, Ángel Rama reseña los ganadores del concurso en los diferentes géneros. Al comentar Chulleca, Rama insiste en la cuestión del realismo y su relación con la militancia política. También resalta que Getino es uno de los pocos autores que cuenta en sus relatos la vida de los proletarios: "Pero además es Getino uno de los pocos escritores - quizá debido a su conocimiento directo- que introduce en sus relatos personajes proletarios y el medio ambiente correspondiente; sin que se huela el pintoresquismo y el revoque literario. No quiere decir que se trate de estampas naturalistas, mansas y descriptivas; al contrario, la tónica dominante es la de un espíritu rebelde, agresivo, con la cual el autor contempla y agita la realidad. Quizás en definitiva la invente, pero es una invención literariamente válida porque nos sentimos llamados a suscribirla" (Rama 1964: 31). 
del Plan de Lucha por medio de una masiva ocupación de establecimientos laborales en todo el país (Schneider 2013: 44).

Este plan incluyó la toma de 11 mil empresas y en él participaron cerca de 4 millones de trabajadores (44). Este tipo de tomas se habían convertido en herramientas de presión muy efectivas por parte del movimiento obrero frente a las patronales. El último cuento del libro es ambientado en una de estas tomas fabriles.

Antes de pasar al análisis concreto de los cuentos vale la pena hablar un poco sobre lo que sucedía en Cuba, y lo que podría significar en Argentina un premio entregado desde el país de la Revolución. Lo primero que habría que nombrar son las conexiones que existían entre El Escarabajo de Oro, Cuba, y la revista de la Casa de las Américas. Abelardo Castillo, director de la revista, ya había recibido una mención en el concurso de cuento en 1961 con su libro Las otras puertas. La revista publicaba información proveniente de Prensa Latina, órgano periodístico de la Revolución Cubana (Calabresse 2006: 47), al tiempo que defendía tal revolución de manera explícita y combativa:

El Escarabajo..., año 1, no 2, julio-agosto 1961, presenta un editorial eminentemente político, abriéndose con la consigna "...con la Revolución cubana no se simpatiza, a la revolución cubana se la defiende", tema de intenso debate que invade ampliamente la opinión pública, pues es el momento en que se evidencia que la revolución liderada por Castro no ha sido meramente un golpe de estado para derrocar al corrupto régimen de Batista, sino un camino al socialismo (Calabresse 2006: 47).

Es precisamente en 1961 cuando la dirigencia cubana explícitamente se declara marxista-leninista. Desde la revista de la Casa ya para ese momento se había establecido una especie de red de publicaciones de izquierda que replicaban artículos, entrevistas, debates (Gilman 2003: 83, 84) y que poco a poco iban consolidando un frente de apoyo intelectual y cultural a la Revolución cubana desde diferentes países latinoamericanos.

También, desde estas publicaciones se iba construyendo una conciencia continental: "La tarea de latinoamericanización de la cultura y la 
creación de América Latina como espacio de pertenencia fue sumamente exitosa, a tal punto que permitió que fuera verosímil la oposición entre 'nacional' y 'latinoamericano', con beneficio para el segundo término" (Gilman 2003: 85). Este proceso de "latinoamericanización" tendría una de sus cumbres precisamente en 1964 -año del premio a Getino-cuando desde la revista Casa de las Américas se anunciaba el nacimiento de la nueva novela latinoamericana. ${ }^{6}$ Así, pues, el premio en Cuba no sólo reconfirmaba a Getino como joven perteneciente a un sector intelectual que se acercaba a una nueva izquierda en el país, sino que también lo colocaba como un novel autor latinoamericano en proceso de consagración. Como se había visto, el "realismo" que se esgrimía desde El Escarabajo de Oro era una forma de enfrentarse a los liberales del grupo Sur, y de manifestar ciertas "realidades" que se intentaban reprimir. En el ámbito latinoamericano la cuestión del "realismo" también era discutida álgidamente entre los escritores que apoyaban en esos primeros años a la Revolución. Como bien lo indica Gilman, en general hubo entre la intelectualidad de izquierda en Latinoamérica un fuerte rechazo hacia el soviético "realismo socialista", pero aun así se intentaba definir una forma de escritura que, sin la carga normativa del estalinismo, fuera "realista" y "novedosa" al mismo tiempo (Gilman 2003: 313-318). Los cuentos de Chulleca, con sus retratos más o menos desencantado de la vida fabril y obrera quedan, como se verá, en un lugar ambiguo en ese debate, pues aunque no son "novedosos" en su forma narrativa, tampoco tienen las características ideológicas adecuadas para considerarse ejemplos de la estética comunista.

Como se decía, en Argentina, el año del premio, las organizaciones sindicales habían estipulado un poderoso plan de resistencia a través de la toma de las fábricas. El último cuento del libro de Getino hace el relato de una toma, desde el punto de vista de un adolescente obrero. Al igual que con "Le decían 45", en este cuento no se hace una descripción heroica del obrero que protesta. Antes que ser un relato emocionante o tensionante,

6 En el número 26, de octubre de 1964, se publica el artículo "Diez problemas para el novelista" de Ángel Rama, texto pionero en las discusiones sobre la importancia del género en la Latinoamérica del momento. 
en donde se expongan los riesgos de enfrentar a la policía o a los patrones, o en donde se muestre algún tipo de evolución política o intelectual dentro de los obreros que organizan la protesta, "La ocupación" muestra la toma de la fábrica como un evento casi familiar, anecdótico, intrascendente. El adolescente aprovecha la ocasión para hablar sobre la muerte de su padre - antiguo trabajador de la misma fábrica-, sobre lo mucho que lo querían los compañeros, o para describir el tipo de relaciones de colaboración o competencia que se construyen al interior de una fábrica. En la toma de la fábrica, la organización de los obreros en protesta no es asumida por ningún sindicato: es más o menos espontánea, y casi todo ocurre mientras el delegado del sindicato sale de la fábrica a consultar con la dirigencia sobre el paso a seguir. La toma termina cuando el delegado llega y les informa que el sindicato no les dará su apoyo esta vez. Esta noticia influye de manera definitiva entre los organizadores de la toma, y ceden entonces a las presiones de la policía, que abre la fábrica y permite que los obreros desocupen sus instalaciones.

Tal vez las frases más significativas del cuento son las últimas: "Vuelvo a sentarme bruscamente en el cordón [andén]. La fábrica se levanta y viene a golpearme los ojos. Por un instante pareciera tan aquí, tan cercana, que si estiro no más ligeramente la mano, estoy seguro, alcanzaría a tocarla" (Getino 1964: 126). Esto es lo que nos cuenta el adolescente, sentado frente a la fábrica, un rato después de que la toma ha concluido. La frase es significativa en cuanto pone de relieve, paradójicamente, la relación de lejanía que el adolescente tiene con la fábrica: la ilusión de "alcanzar a tocarla" obviamente tiene un significado metafórico. La frase impacta en cuanto que esa lejanía metafórica contrasta violentamente con el ambiente familiar y de camaradería que se vivía dentro de la fábrica, y con la manera en que los obreros se relacionan con ese espacio. Recuerdos íntimos de infancia, amistades, historias, transcurren allí, e incluso la protesta es narrada con un tono de calidez y cercanía que daría la impresión de que no hay en esa situación demasiadas cosas en juego: no se habla de la posibilidad de despidos, o de la posibilidad de violencia policial. Más bien se muestra cómo un obrero italiano llora porque no puede salir a saludar a su 
pequeño hijo, o las bromas que entre ellos mismos se gastan. En ese "alcanzar a tocarla" pareciera que se insinuara toda la tensión política y social que el adolescente deja por fuera de su relato: el lugar donde ocurren las vidas de los obreros pertenece a los patrones, y aunque aquellos tengan una relación entrañable con la fábrica, en realidad no pueden "tocarla": no les pertenece. Desde este punto de vista, la toma realizada en el cuento sería una especie de natural intento por recuperar lo que íntimamente se siente como propio.

Aquí es importante recordar que en el relato la toma no es organizada por ningún sindicato, lo que hace que los intereses políticos que necesariamente se manejan en esas instituciones queden por fuera de las motivaciones de la toma y que, además, son precisamente esos intereses los que influyen de manera inequívoca para la finalización de la protesta. Esta manera de desligar la organización de los obreros del accionar del ente sindical, e incluso de oponerlas, es una forma de "naturalizar" la acción de la toma, en el sentido de darle un carácter espontáneo y casi necesario dentro del transcurrir de las vidas de quienes trabajan allí, puesto que tampoco se hace mención a ningún partido político. Esto es importante en cuanto tematiza y se enfoca en el sentir obrero y la manera en que éste se puede articular a acciones que necesariamente tienen causas y consecuencias políticas, aunque estas últimas no aparezcan de manera explícita. Otros cuentos tratan también de la manera en que los trabajadores se relacionan con máquinas que pertenecen a la fábrica, y cómo esa relación de alguna manera "deshumaniza" a los obreros, al tiempo que humaniza a las máquinas. En otros, la relación con un animal o alguna situación particular pone en entredicho la humanidad de los protagonistas. Conceptos marxianos como "enajenación", "fetichización" y "cosificación", o la tensión entre "trabajo vivo" y "trabajo muerto", parecen ilustrarse en varios de estos cuentos. 


\section{MARX Y LA "DESHUMANIZACIÓN"}

Los cuentos de Getino nos recuerdan muy vívidamente fragmentos de la obra de Karl Marx sobre el trabajo humano cosificado y objetivado para el mismo obrero, tema que desarrolló también el filósofo marxista George Lukács en Historia y conciencia de clase (Lukács 1969 [1923]). En estos textos se argumenta que con el tipo de producción capitalista y la aparición de la estructura social basada en el mercado de mercancías, el trabajo humano se convierte en una mercancía más para ser vendida, y esto conlleva consecuencias negativas para el trabajador. Por ejemplo, que su capacidad productiva se vea desligada del resto de sus facultades humanas, y que tal capacidad necesariamente se "deshumanice", en cuanto hace parte de un sistema racionalizado de producción. Para el análisis de estos cuentos, los conceptos de "cosificación", y la tensión entre "trabajo vivo" y "trabajo muerto", mostrarán cuestiones primordiales de la visión sobre la relación entre el obrero y los medios de producción en el capitalismo en los cuentos de Getino. Mientras la cuestión de la cosificación la mostraremos a través de los textos de Lukács y con ayuda del texto sobre este concepto elaborado por Gerardo Ávalos Tenorio "Actualidad de Marx. Cosificación, fetichismo y enajenación" (Ávalos 2012), el asunto de la contraposición dialéctica entre los dos tipos de trabajo que se enfrentan en la labor del obrero se observará a través de un texto de Enrique Dussel llamado "Trabajo vivo y filosofía de la liberación" (Dussell 1994). Es muy importante anotar que el hecho de que sea precisamente uno de los autores más representativos de la corriente descolonial del pensamiento latinoamericano quien nos muestre con claridad la importancia de la tensión

Óscar Terán hace un panorama de las corrientes marxianas que son rescatadas por diferentes publicaciones y debates de izquierda en la primera mitad de la década de los sesenta en Argentina, entre ellos por supuesto Sartre, pero también se hizo un rescate de las propuestas de Antonio Gramsci, de George Lukács y de algunos textos de mismo Marx como los "Manuscritos económico-filosóficos de 1844" que "ponían el acento sobre el concepto de enajenación y postulaban la recuperación de aquella pérdida mediante la apelación de una esencia humana de corte feuerbachiano" (Terán 1991: 105). 
entre los dos tipos de trabajo en el desarrollo del pensamiento de Marx no es en absoluto casual. Getino pasará de exponer algunas nociones marxistas en este libro de cuentos, a plantear interrogantes que apuntan a la descolonización del pensamiento y la cultura a través de sus películas, apenas unos años después.

Dos cuentos exponen de manera directa la relación del obrero frente a la máquina, cómo en esta relación las condiciones laborales "deshumanizan" al protagonista. Estos cuentos son "El torno" y "El dispositivo". En el primero un obrero se "despide", muy emotivamente, del torno con el cual trabajó durante 15 años en una fábrica; en el segundo un operario debe pasar una prueba técnica, arreglando un extraño dispositivo, para conservar su trabajo. En ambos cuentos se nos presenta la situación desde el punto de vista del trabajador, y así vemos la manera en que se entabla la particular relación con la máquina. Por ejemplo, al comenzar el relato "El torno", se nos introduce al tipo de reflexión que realizará el protagonista, de la siguiente manera: "Un enjambre de manijas que una madrugada quince años antes le hizo secar la boca de espanto y que ahora le eran tan simples, tan propias, no sabría cómo decirlo, quizás como su pierna, como su brazo, o como el Cacho, sí, eso es: como el Cacho. Y aún más. Porque el Cacho es su hijo y no falta mucho para que lo llamen de la conscripción, pero lo entiende menos; le es más ajeno. El torno, no. El torno es otra cosa" (Getino 1964: 86). El obrero tiene así una relación más cercana y familiar con el torno que con su hijo. Además, el torno casi que hace parte de su cuerpo "como un brazo", y el obrero llegaba a "conocer los latidos del torno como su fueran sus propios latidos" (Getino 1964: 87). Esta humanización de la máquina tiene su contraparte obvia: la "maquinización" del humano: "Y hoy se lo llevan. Ahora que está un poco viejo se lo venden a los paraguayos. Vos lo hacés vivir y luego sin consultarte nada, firman un acta y chau. Antes era distinto. Ahora lo ven a uno un poco inútil y ya sea hombre o torno son capaces de joderlo. El respeto que había antes no lo hay hoy. Hoy la gente... No sé" (1964: 89).

Esta relación entre el trabajador y la máquina es expresada en varios textos de Marx y, siguiendo a Dussel en su artículo, se constituye en uno 
de los ejes conceptuales más importantes en la obra del alemán. Tal relación expresa la tensión dialéctica entre el trabajo materializado en los medios de producción capitalista -las máquinas - y la capacidad de trabajo del obrero - el "trabajo vivo"- Dussel muestra cómo el "trabajo vivo" es absorbido por el "trabajo muerto", de manera que pueda convertirlo en capital. En este proceso, el obrero se ve convertido en mercancía, en cuanto es valorado apenas por las características que le permiten pertenecer al proceso de producción capitalista, negándole así la totalidad como ser humano. Dice Dussel: Para "Marx, como vamos viendo, el 'trabajo vivo', no es el trabajo en general, sino el trabajador mismo como subjetividad, como persona, ante el trabajo objetivado, cosificado, devenido valor, mercancía, dinero, capital: trabajo muerto" (Dussel 1994: 209). Más adelante, Dussel caracteriza explícitamente la tensión entre estos dos tipos de trabajo en la obra de Marx como una inversión: se humaniza al "trabajo muerto" y se cosifica al "trabajo vivo" (215), tal y como lo vemos en los cuentos de Getino. Pero esto no es todo. Dussel encuentra en tal tensión el núcleo de toda la propuesta conceptual de Marx, e interpreta el concepto de "trabajo vivo" como uno de los más importantes para entender la crítica al capitalismo que se plantea en la obra del alemán (Dussel 1994: 216). Dussel dice que el "trabajo vivo" como exterioridad de los mecanismos del capital, esto es, como el elemento desde el cual se desarrolla la crítica a todo el sistema capitalista, es totalmente compatible con sus planteos de la "Filosofía de la liberación". ${ }^{8}$ Para Dussel, la exterioridad del trabajo vivo frente al capital parece relacionarse muy directamente con la exterioridad de Latinoamérica frente a los centros de producción capitalista (1994: 218). Es decir, la cuestión de la humanidad del obrero se relacionaría con la condición periférica y de "otredad" de la sociedad latinoamericana, en cuanto que ambas son exterioridades que de alguna manera se contraponen al sistema capitalista, y que de alguna manera ambos - la

8 "La filosofía de la liberación es entonces el primer movimiento filosófico que comienza la descolonización epistemológica de la filosofía misma, desde la periferia mundial, criticando la pretensión de universalidad del pensamiento moderno europeo y norteamericano situado en el centro del sistema-mundo." Solís et al. 398-399. 
vida del obrero y Latinoamérica - han sido subsumidos por el capitalismo, haciéndoles perder su "ser" (1994: 217). Esto es importante en cuanto emparenta la mirada marxiana de la vida del obrero que aparece en los cuentos de Getino con el desarrollo de las concepciones descoloniales del conocimiento, y con el latinoamericanismo que se respiraba en la región en esas fechas.

Por otro lado, en su artículo, el politólogo Ávalos Tenorio recuerda que las máquinas como medios de producción son materializaciones del capital producido con el trabajo de los obreros: "el trabajo crea la riqueza objetiva [el capital] succionada por su propio ser pero puesto negativamente: entonces el trabajo es capital; en el mismo acto, el individuo que trabaja se empobrece humanamente. Su vida le pertenece al capital: la vida del obrero alimenta los objetos que componen al capital" (Ávalos 2012: 17). En el cuento "El dispositivo" el obrero puesto a prueba, bajo la presión de la posibilidad de perder su empleo, casi delira que los componentes del mecanismo que debe arreglar se han puesto de acuerdo para sabotearlo: es decir, les da vida en su imaginación, y ellos se ponen en su contra: "Las piezas se han puesto de acuerdo, estoy seguro [...] El tornillo no lo escuchaba [... La caja de metal osciló por su cuenta como si tuviera vida propia. Temblaba, respirando ¿o no?" (Getino 1964: 95). Este "alimentar" a los objetos del capital, que tan vivamente se observa en los cuentos, profundiza en la forma en que el "trabajo vivo", es decir, el cuerpo del trabajador, termina por ser absorbido por los mecanismos de reproducción del capital: los cuentos de Getino muestran no sólo la tensión entre estas dos formas de trabajo, sino también las consecuencias que tal tensión tiene en la subjetividad alienada de los trabajadores.

Esta consecuencia negativa para los obreros es expuesta claramente por Lukács, quien profundiza en la manera en que al ser insertados en el tipo de producción capitalista, los trabajadores pierden su esencia humana. Esto es lo que Lukács llama "cosificación": "esa auto-objetivación, esa conversión de una función humana en mercancía, revela con la mayor crudeza el carácter deshumanizado y deshumanizador de la relación mercantil". (Lukács 1969: 11). Ávalos relaciona este asunto con la "toma de 
conciencia", y asume que ésta última vendría siendo la solución para los problemas que generan los dos primeros fenómenos (Ávalos 2012: 18). Tal "toma de conciencia" es el entender que el capital pertenece legítimamente al obrero, en cuanto ha sido enajenado por el patrón a través de la plusvalía, y conlleva, a través del entendimiento racional, a que el obrero se sienta parte de su clase social y actúe en beneficio de ella. Decíamos párrafos arriba que en los cuentos de Getino se prescinde de cualquier tipo de alusión a la politización de los obreros, a su pertenencia a algún tipo de partido político, y las rebeldías que los personajes plantean generalmente al final de los relatos (en "Le decían 45" el personaje arroja la piedra; en "El torno" el obrero termina su monólogo interior valorando a su hijo por encima de la máquina; en "El dispositivo" el operario destruye de un martillazo el aparato, en "La ocupación" el adolescente casi "toca" la fábrica) no vienen dadas por una "toma de conciencia" en el sentido racional del término. Esto es llamativo no sólo por lo que señala Ávalos, en cuanto a que la "toma de conciencia" es, marxianamente, de alguna manera una solución a la condición oprimida del obrero, a su "cosificación", sino que, en el contexto histórico donde Getino se forma políticamente, y en el que son galardonados sus relatos, la politización y la educación sindical hacían parte importante de las dinámicas gremiales. Según Schneider:

La gimnasia de tomas de fábrica, aún conducidas por la CGT, tuvo el efecto de politizar (por momentos) a muchos trabajadores hacia posturas radicalizadas. No sólo por la experiencia, también porque una actitud combativa generaba espacios y puntos de contacto con militantes peronistas y de corrientes de izquierda. Las jornadas de protesta permitieron que los trabajadores transiten de una lucha sindical a una lucha política que englobe al conjunto de la clase obrera (2013: 46).

También Gabriella Scodeller muestra en su artículo "(Des) encuentros en las experiencias de formación político-sindical en los años sesenta en Argentina" (2013) la manera en que distintas vertientes de los movimientos obreros se interesan en fortalecer y sistematizar sus mecanismos de formación política y sindical. 
¿Por qué entonces Getino excluyó de sus cuentos estas realidades? ¿Por qué razón algunas lógicas marxianas toman cuerpo en los conflictos de sus protagonistas, mientras la resolución que el marxismo plantea a tales conflictos (la "toma de conciencia" y la militancia) quedan excluidas? ¿De qué manera esta característica de los relatos se ajustaba a las líneas ideológicas de El escarabajo de oro y del concurso de la Casa de las Américas? A comienzos de la década de los sesenta, a raíz de la declaración de Fidel Castro en cuanto a que la Revolución cubana era un camino al socialismo, se encendió en Cuba (y por ende en buena parte de Latinoamérica) el debate sobre la manera en que la dirigencia política de la isla incidiría sobre su desarrollo cultural. A este respecto, y debido también a los necesarios acercamientos al Partido Comunista cubano que la dirigencia castrista debió hacer para fortalecerse, el fantasma del estalinismo y del realismo socialista recorrió las discusiones, en las que, por supuesto, apareció el tema de los premios de la Casa de las Américas. Al decir de Claudia Gilman, los temores de los escritores no eran insostenibles. Según la investigadora, si se revisan los premios de la Casa entre 1960 y 1962, los textos "con sus héroes positivos, satisfacían las demandas de salud ideológica, pero no eran, sin duda, lo que la mayoría de artistas esperaban que se alentara como programa estético" (Gilman 2003: 194). Temáticamente, también según Gilman, eran textos que satisfacían a la porción comunista que Castro colocó en las instituciones de la revolución como mecanismo de estabilización interna. Este tipo de arte se oponía a otro que aceptara los aportes "vanguardistas" (2003: 193) y que era defendido por muchos de los intelectuales más reconocidos de la red de apoyos a la Revolución, como por ejemplo Julio Cortázar. Si bien los cuentos de Getino están lejos de tener héroes "positivos", y fueron premiados dos años después de los mencionados por Gilman, habría que aceptar que tanto temática como formalmente fácilmente se podrían entender dentro de la línea estética que se asociaba con la fracción comunista de las instituciones cubanas. 
Sin embargo, a diferencia de los textos mencionados por Gilman, los de Getino no dan un apoyo explícito a ninguna institución política. Este pequeño pero significativo distanciamiento podría estar relacionado tanto con los debates que se daban en Cuba desde 1961 sobre la libertad artística, como con la evolución de la "nueva izquierda" en Argentina. En Cuba, el espacio para una literatura más "libre", en el sentido de autónoma de la dirigencia política, se fue abriendo en medio de los debates, sobre todo después de que Castro pronunciara sus "Palabras a los intelectuales" en 1961 (Gilman 2003: 195-196). En Argentina, como se ha mencionado ya, cierta izquierda vinculada anteriormente al Partido Comunista argentino se había desligado para avanzar hacia una especie de "marxismo nacionalista" (Sigal 1991: 192; Terán 1991: 100). La no mención del Partido Comunista ni del peronismo como soluciones explícitas para las rebeldías personales de los protagonistas podría verse como síntoma de ese recorrido de buena parte de la intelectualidad crítica argentina. Como dice María Rosa Oliver, una de los jurados que concedió el premio a Chulleca, "la ráfaga revolucionaria que está transformando el mundo" aparece en el libro, y aunque "no se nombra este soplo", "se siente su fuerza en hechos cotidianos" (Getino 1964). ${ }^{9}$ Es decir, el "soplo" revolucionario permanece innominado, latente en los protagonistas, sin que el autor se resuelva a

9 En la primera edición del libro, en la colección "Concurso" de la Casa de las Américas, en la contratapa se lee el párrafo escrito por María Rosa Oliver sobre el conjunto de cuentos que ella, como parte del jurado del concurso, premió. Dice: "Esta recopilación de cuentos lleva por título el del primer relato. Es el único que está por fuera del tiempo pues el árido territorio del noroeste argentino donde aparece la Chulleca, poco ha cambiado con los años. En cambio los demás cuentos se basan en la mutable y casi siempre dramática realidad de estos días. En el campo argentino de hoy, en Buenos Aires y en sus suburbios, a los que llega, en las personas de europeos desplazados con problemas que lo llevan a la lucha, la ráfaga revolucionaria que está transformando el mundo. No se nombra este soplo. Se siente su fuerza en hechos cotidianos, en las vidas que quiebra o tuerce, en el ímpetu de los que se rebelan contra la injusticia que padecen. Jamás se le siente en los diálogos, tan fieles a los de la vida real que llegan a parecer captados con una grabadora. En Chulleca se revela un escritor nuevo que, de seguir la línea de estos cuentos, enriquecerá, sin duda alguna, la literatura latinoamericana. Su autenticidad, su falta de retórica, su carencia de afán folklórico, así nos lo permiten esperar" (Getino 1964). 
darle una resolución comunista o peronista. Incluso, tal vez, este vacío se deba a que aún no existían, en 1964, instituciones o grupos intelectuales que hubieran asumido ya, del todo, esa mixtura marxista-peronista.

Otros de los cuentos de Chulleca tematizan también la "deshumanización", pero ya fuera del contexto fabril, entre ellos el cuento que le da nombre al libro, y "Rosaura". El primero cuenta la historia de una demente que vive como indigente en un pequeño pueblo, y que es aceptada a duras penas por la comunidad. Cuando un desastre natural obliga a la mayoría de los habitantes a abandonar sus casas y su tierra, Chulleca se queda junto con otros paisanos, que no le permiten enterrar a su hijo muerto, por considerar que ella no era digna de un trato humano: "La Chulleca no podía tener hijos. A lo sumo cría, como los quirquinchos" o "Fue Salustiano quien dijo que la Chulleca no era una mujer, sino un engendro con menos derechos que un perro" (Getino 1964: 3-5). En el segundo se nos muestra una inspección policial a una pequeña escuela de teatro, y el narrador debe esconder un poema que su novia le ha regalado. Las reflexiones del personaje que nos cuenta la historia transmiten la rabia que le produce la actitud policial: como si fuera algo normal y cotidiano, de manera subrepticia los despojan a todos de su dignidad humana, y es este extraño tipo de hipocresía lo que hace difícil que los que han sido violentados puedan reaccionar en contra de tales abusos: "¿Qué era lo que nos deshumanizaba? ¿Era acaso la metralleta de los policías? ¿Podía ser el temor de que nos llevaran a la Federal? Pienso que era otra cosa. Era la forma natural en que ellos habían entrado. Nos sentíamos cosa humana... Y no lo éramos" (Getino 1964: 112).

En ambos cuentos también hay, al final, una pequeña forma de rebeldía o esperanza, a través de la cual parece prometerse al futuro algo mejor. En "Chulleca" la demente, ya sin posibilidades de darle sepultura como se debe a su hijo, decide enterrarlo en el arenal donde se enfrentó a los otros pobladores. A la pregunta del narrador de por qué lo entierra allí, ella responde: "No lo entierro - musitó, baboseándose. Puso sobre las tolas una rama seca de álamo. - Lo planto-dijo. Y con andar muy lento, como si no la corriera la prisa, se fue a morir a su choza" (Getino 1964: 
7). El acto de plantar un muerto por supuesto que insinúa la posibilidad de que en el futuro produzca una cosecha: una esperanza. En "Rosaura", el protagonista, dispuesto después de la requisa a discutir con su novia sobre el poema que lo había puesto en peligro, se rinde ante la mirada profunda y sincera de ella, como si ese amor triunfara finalmente sobre el poder policial (muy comparable con la manera en que el protagonista de "El torno" al final valora nuevamente a su hijo). Si bien en los cuentos que tratan sobre el ambiente fabril la "deshumanización" se da a través de la comparación con las máquinas, en los demás cuentos la comparación se hace con animales. Es el caso de los dos cuentos anteriores, y también sucede en "La patada". En este último, se narra la manera en que la paciencia de un empleado se va agotando a medida que su jefe - que es también su vecino- lo maltrata. Llega un momento en que el protagonista asesina a su jefe, pero en la narración lo que más impacta a aquél es que, justo después del asesinato, su propio gato aparece y recibe una inconsciente y salvaje patada de su parte. Eso es lo que perturba al narrador. El jefe es puesto por debajo de un gato en el relato del asesino. En este sentido, este cuento es el único que deshumaniza a quien comete la injusticia, y no al revés. Pero no es el único en el que de alguna manera la injusticia que se relata en el cuento es vengada al final.

También en "Decúbito dorsal" y en "Perico" los protagonistas logran, más allá de un gesto de rebeldía, una especie de venganza o de liberación. El primero, tal vez el más fantástico del libro, un hombre enferma produciendo una tos pestilente, justo después de encontrar a su mujer acostándose con su mejor amigo. La tos produce un aroma tan desagradable que el personaje es aislado en el hospital, y utiliza esa fetidez, después de aprenderla a controlar como a un ser externo a él mismo, para vengarse en la visita que le hacen los traidores. En "Perico" dos niños indigentes piden monedas, juegan y trabajan en la calle, y al final, en un gesto agresivo de competencia y liberación, ambos tiran su dinero al piso como retando al otro a recogerlo, y luego salen felices y sin un peso en el bolsillo corriendo hacia la naturaleza. La deshumanización en estos relatos no es tan explícita como en los demás. Sin embargo, en "Decúbito dorsal", extrapolando 
un poco la lectura marxiana de los cuentos sobre fábricas, la personificación que el protagonista hace de su propia enfermedad, como si un nuevo ser hubiera crecido desde su propio cuerpo para hacerle daño, puede ser entendida también como una metáfora de la objetivación de la mano de obra del operario, cuyo trabajo, materializado en capital, se le vuelve en contra, de la misma manera en que las fantasías del obrero en "El dispositivo" daban vida al aparato que no le permitiría conservar su trabajo:

Resolví llevar a delante mi plan. Dejé que la tos satisficiera sus caprichos, mientras tanto la estudiaba pacientemente. Adiviné sus líneas, sus contornos que se me fugaban. Entonces recurrí a mi tos y mi tos vino delirante y ronca. [... ] Mi universo creció; rebasa mis límites, se expandía. [.. . ] como si estuviera oliendo fritos, mi mujer se puso pálida, su tez amarillenta como la cera. Supe que le venían arcadas. Reí como nunca para mis adentros (Getino 1964: 70-71, 73).

La particularidad acá es que el protagonista es capaz de dominar ese aspecto negativo de su propio ser y transformarlo en un arma para vengar la traición que había sufrido y que precisamente le había provocado la enfermedad. Siguiendo la metáfora marxiana, sería como si el obrero, finalmente, se adueñara del capital —el producto de su propio cuerpo-y lo utilizara para sus propios fines. Es importante resaltar que si esta solución se hubiera dado en uno de los cuentos sobre obreros - por ejemplo, que la toma de la fábrica hubiera sido exitosa - mantener el alejamiento del ámbito expresamente político hubiera sido mucho más complicado, en cuanto tal recuperación necesariamente sería un logro colectivo.

\section{LA MIGRACIÓN EUROPEA EN LOS CUENTOS}

Otro tema que aparece en varios cuentos es el de la migración. En los cuentos "El coronel Tsnik" y "10.018", el personaje principal es un migrante, y en "Abelardo" y "Rosaura" hay un par de menciones significativas de este fenómeno. En el primero se nos cuenta la llegada de Tsnik a Buenos 
Aires, un alto mando al parecer del ejército aliado, para perecer de miseria y pobreza sin recibir una ayuda del consulado de país. En "10.018" se observa la historia de vida de Casimiro, un prisionero del ejército nazi que es obligado a combatir junto con sus captores, y que luego de azares de la vida termina como capataz de una construcción petrolera en Tucumán, al mando de un patrón que al parecer, al final del cuento, se revela como un exnazi. "Abelardo" cuenta la historia de un obrero que se hace cargo del negocio que, junto con un español republicano llegado a la Argentina, montan juntos. Después de ser dirigente sindical, Abelardo se dedica al restaurante y se independiza del movimiento obrero. El cuento transcurre durante una manifestación, en donde Abelardo corre a salvar su negocio y termina muerto sin que se aclare si cae por balas del Estado o por una pedrada proletaria. En "Rosaura", uno de los personajes que es interrogado y requisado por los policías en la escuela de teatro es un español al que se le pregunta si es republicano, a lo que responde, asustado, que no, faltando a la verdad tal vez por miedo a la represión policial.

Con excepción de Casimiro - a quien se le muestra tratando de sabotear una huelga - todos parecen estar más o menos alejados de la acción política en Argentina. Además, sus finales son trágicos: o mueren o se dan cuenta de que trabajan para un exnazi. Son personajes que, al contrario de lo que había sucedido con Getino, no se involucran en el devenir político del nuevo país que los acoge. Ya se ha dicho que, al momento de publicar los cuentos, Getino se ha alejado de la militancia en los centros de exiliados republicanos, y ha emprendido un camino que iba del socialismo antiperonista al nacionalismo marxista, a través de la militancia sindical: seguramente había abandonado ya aquella mirada que identificaba a Perón con Franco, para empezar, como muchos otros intelectuales, una lectura de aquél que lo acercaba a Fidel Castro, en cuanto líder popular que podría dar un giro hacia el marxismo (Sigal 1991: 201) como lo había hecho el cubano en 1961. De esta manera, Getino en su libro pareciera estar cerrando un capítulo de su propia militancia, poniéndole fin a una interpretación de la realidad latinoamericana desde una mirada europea, para hacerlo desde un punto de vista mucho más afincado en los devenires 
políticos propios de nuestro continente. A través de una mirada marxiana que, según Dussel, puede emparentarse directamente con una reflexión latinoamericanista sobre el capitalismo mundial, los cuentos de Chulleca muestran un proceso de viraje en la forma de entender las dinámicas políticas y sociales argentinas por parte de Getino: un distanciamiento con los planteamientos estéticos comunistas ortodoxos, y un acercamiento a los movimientos sindicales peronistas. Getino no continuará escribiendo literatura, pero en sus películas (como La bora de los bornos) mostrará de manera explícita la relación entre marxismo, peronismo y latinoamericanismo. Podemos entender, entonces, Chulleca como una especie de bisagra en las concepciones políticas de Getino: entre el republicanismo y el peronismo, entre una izquierda ortodoxa a una nacionalista: finalmente, entre Europa y Latinoamérica.

ANEXO: EL PASO AL CINE

Getino decidió filmar su primer documental el mismo año en que su libro de cuentos ganó el prestigioso concurso de Casa de las Américas. En 1964 ya se encontraba estudiando cine en la Asociación de Cine Experimental de Buenos Aires (ACEBA). Ese mismo año su corto documental Trasmallos ganó el concurso de esa misma asociación, contra toda expectativa. El concurso era para egresados de la escuela o que estuvieran ya en tercer año - Getino estaba en el primero-, y en general no se consideraba que se pudiera presentar un film documental. Esto debido a que, desde los intereses del Partido Comunista (ente que influía fuertemente en la ACEBA), se quería preparar a los estudiantes para producir ficciones capaces de entrar a competir con el cine industrial. Para Getino y el grupo de compañeros que filman Trasmallos, esto era una locura, puesto que requería unas condiciones técnicas y unos presupuestos dificilísimos de alcanzar (Campo 2013: 127). Así que se enfrascan en la producción de un film que va en contravía de lo que se planteaba institucionalmente. 
Más que entender el porqué del viraje de la literatura al cine, o si en efecto este viraje existió realmente, pues parece ser más bien un desarrollo paralelo, lo que puede ser relevante es observar cómo las posturas que Getino ocupa en el campo literario y en el campo fílmico son hasta cierto punto homólogas, por lo menos en su relación con el devenir político de Argentina y Latinoamérica. La cuestión de las homologías entre campos es tratada por Bourdieu para explicar, por ejemplo, la manera en que algunos sectores intelectuales se sienten identificados con sectores oprimidos de la sociedad. Bourdieu asegura que, a pesar de que el campo intelectual hace parte del sector dominante de la sociedad, es la parte dominada de tal sector dominante. Así, surge una homología entre intelectuales y explotados, en cuanto ambos son dominados, aunque de diferente manera (Bourdieu y Wacquant 1991: 161). Es decir, la homología surge cuando la posición relativa de dos sectores sociales, en cada uno de sus campos específicos, es la misma, en el conjunto de relaciones que constituye cada campo. En el caso específico de Getino, el lugar que ocupa el documental en el campo cinematográfico es homólogo al que ocupa el tipo de realismo de Chulleca en el campo literario. Como se veía, Chulleca hace descripciones "realistas" de la vida obrera sin plantear una solución política concreta, se distancia hasta cierto punto de los planteamientos de la estética comunista, y su premio en Cuba lo ubica en la institución que cataliza las discusiones y los debates de la izquierda latinoamericana. Si comparamos estas características con lo que planteaba el documentalista Fernando Birri en su Manifiesto de Santa Fe, ${ }^{10}$ el resultado es bastante interesante: el documental tampoco debe plantear soluciones concretas sino sólo mostrar la "realidad", y se le inscribe también en una lucha de

10 En 1964 Birri publica su Manifiesto de Santa Fe, en donde afirma que el tipo de cine que se necesitaba en Latinoamérica, socialmente hablando, era el documental, pues las causas del atraso en el continente son también conocidas: "colonialismo, de afuera y de adentro. El cine de estos países participa de las características generales de esa superestructura, de esa sociedad, y la expresa, con todas sus deformaciones. Da una imagen falsa de esa sociedad, de ese pueblo, escamotea al pueblo: no da una imagen de ese pueblo. De ahí que darla sea un primer paso positivo; función del documental. ¿Cómo da esa Imagen el cine documental? La da como la realidad es y no puede darla de otra manera" (Paranaguá 2003: 456). 
carácter continental. Cabe decir que esta concepción sobre el documental va cambiando, como se ve en la misma obra de Getino, a medida que avanza la década, y cada vez va proponiendo soluciones políticas más concretas. Como agregado cabe recordar que Getino decidió filmar Trasmallos desafiando las indicaciones de su escuela, que se alineaba con el Partido Comunista. Así, el lugar que Chulleca ocupaba en el campo literario era similar al que ocuparía un documental como Trasmallos, por lo menos en cuanto a la posición política que representarían las características de cada una de esas obras: si al interior de cada campo las cuestiones políticas se traducen de maneras específicas, Getino en ese sentido no sólo fue coherente al mantener su postura política en ambas obras, sino que también logró aprehender cómo expresarla en los códigos específicos de cada uno de los campos.

Trasmallos muestra la vida de una familia pescadora de Quilmes, y fue filmado por un grupo de compañeros de estudio de Getino que se reunieron bajo el nombre de Grupo de los 7. Gracias a este corto, Getino se incorporó al equipo de producción del italiano Valentino Orsini, que estaba interesado en hacer una ficción sobre la clase alta argentina llamada Los que mandan. Sin embargo, el proyecto no obtuvo los fondos que necesitaba para realizarse y se hundió. Fue allí en donde Getino se conoció con "Pino" Solanas y donde empezaron a concebir el proyecto que desembocaría en su film más conocido: La hora de los hornos, en 1968. Ambos provenían de una militancia de izquierda que se distanciaba del Partido Comunista.

\section{BIBLIOGRAFÍA}

Ávalos Tenorio, Gerardo. "Actualidad de Marx. Cosificación, fetichismo y enajenación" Reencuentro 64 2012: 12-20. En línea en: http://www. redalyc.org/articulo.oa?id=34023236002 (Consultado el 23 de marzo de 2019). 
BeTHel, LesLie (ed.) Historia de América Latina. Tomo 15. El cono sur desde 1930. Madrid: Cambridge University Press, 2002.

BOURDIEU, PIERRE. Las reglas del arte. Barcelona: Anagrama, 1992. y LOIC WACQUANT. Una invitación a la sociología reflexiva. Buenos Aires: Siglo XXI, 2005 [1991].

CALABRESSE, ElISA. "Las revistas de Aberlardo Castillo. Un proyecto cultural alternativo". CELEHIS-Revista del Centro de Letras Hispanoamericanas 17 (2006).

CAMPo, JaviER. "Entrevista a un valeroso". Cine documental 7 (2013).

DieGO, J. L. DE. Campo intelectual y campo literario en la Argentina [1970-1986]. Tesis Universidad Nacional de La Plata. Facultad de Humanidades y Ciencias de la Educación. 2003. En línea en: http://www. fuentesmemoria.fahce.unlp. edu.ar/tesis/te.150/te.150.pdf (Consultado el 25 de noviembre de 2016).

Dussel, EnRique. "Trabajo vivo y filosofía de la liberación". AAVV. Historia de la filosofía latinoamericana y filosofía de la liberación. Bogotá: Nueva América, 1994.

Getino, Octavio. Chulleca. La Habana: Casa de las Américas. 1964.

. "Chulleca y los del río. Presentación". Artículo en línea disponible en http://octaviogetinocine.blogspot.com.co/2010/06/chulleca-y-los-del-rio.html\# more. (Consultado el 28 de enero de 2018). Gilman, Claudia. Entre la pluma y el fusil. Dilemas y debates del escritor revolucionario en América Latina. Buenos Aires: Siglo XXI, 2003.

Lukács, GeOrg. Historia y conciencia de clase. México: Grijalbo, 1969.

Paranaguá, Paulo Antonio (ed.). El cine documental en América Latina. Madrid: Cátedra, 2003.

RAMA, ÁNGEL. Rodolfo Walsh: la narrativa en el conflicto de las culturas. Ficciones argentinas. Antología de lecturas críticas. Norma: Buenos Aires, 2004.

cas". Marcha (1964): 31.

ROMERO, JosÉ LuIs. Breve historia Argentina. Madrid: FCE, 2013. 
SALINARI, CARLO (sel. y pról.) Marxy Engels: escritos sobre arte. Barcelona: E. Península, 1969.

SCHNEIDER, ALEJANDRO. "Una lectura sobre las organizaciones de base del movimiento obrero argentino (1955-1973)". Archivos de Historia del Movimiento Obrero y la Izquierda 2 (2013): 33-54.

SCODELLER, GABRIELA. "(Des)encuentros en las experiencias de formación político-sindical en los años sesenta en Argentina”. Historia Crítica 50 (2013): 157-181.

SCHWARZSTEIN, DORA. Entre Franco y Perón: memoria e identidad del exilio republicano español en Argentina. Madrid: Crítica, 2001.

Sigal, SiLVIA. Intelectuales y poder en la década del sesenta. Buenos Aires: Punto Sur Editores, 1991.

Solís, N. L. et al. "La filosofía de la liberación". Artículo en línea disponible en http://enriquedussel.com/txt/la\%20filosofia\%20de\%20la\%20liberacion.pdf. (Consultado el 25 de noviembre de 2016).

Terán, OsCar. Nuestros años sesenta. Buenos Aires: Punto Sur Editores, 1991. 
